\section{Infliximab and CT-P13 immunogenicity assessment in PLANETAS and PLANETRAS main and extension studies: utility of laboratory methods description}

Immunogenicity is known to be one of the main parameters to be considered during evaluation of the safety and efficacy of a biologic drug. The recent introduction in rheumatologic therapy of biosimilar drugs requires the comparison to the correspondent reference product (RP) of all their characteristics, included immunogenicity. In particular, immunogenicity of infliximab (IFX) biosimilar CT-P13 and IFX-RP was compared in PLANETAS (in patients with ankylosing spondylitis) and PLANETRAS (in patients with rheumatoid arthritis) main and extension studies. ${ }^{1-4}$ Because of the great interest of clinicians in immunogenicity evaluation and the impact of the assay method used for the detection of the antidrug antibodies (ADAs), ${ }^{5}$ in our opinion, some aspects of the mentioned studies should be pointed out. First, ADAs against both CT-P13 and IFX-RP were assessed by electrochemiluminescence, which is nowadays one of the more used detection methods, because of its high sensitivity and high drug tolerance. ${ }^{67}$ The neutralising capability of detected ADAs was assayed by a flowthrough immunoassay method Gyros Immunoassay (Gyros AB, Uppsala, Sweden), which is a microfluidic platform coupling high sensitivity and high drug tolerance. This technology has several more advantages, being also time saving and able to provide results with very low volumes of sample. ${ }^{8}$ Nevertheless, since this last method is still uncommon in most laboratories, some more description of the principle of the method and some more technical details about its application to the neutralising activity detection should be done, in order to better understand study results, and in order to encourage the diffusion of more performing laboratory methods. In addition, an inhibition test to confirm the specificity of ADAs detected would be clarifying.

\section{Francesca Meacci, ${ }^{1}$ Mariangela Manfredi, ${ }^{1}$ Maria Infantino, ${ }^{1}$ Valentina Grossi, ${ }^{1}$ Maurizio Benucci ${ }^{2}$ \\ ${ }^{1}$ Immunology and Allergology Laboratory, San Giovanni di Dio Hospital, Florence, Italy \\ ${ }^{2}$ Rheumatology Unit, San Giovanni di Dio Hospital, Florence, Italy}

Correspondence to Dr Francesca Meacci, Immunology and Allergology Laboratory, San Giovanni di Dio Hospital, via di Torre Galli 1, Firenze 50143, Italy; francesca. meacci@uslcentro.toscana.it
Competing interests None declared.

Provenance and peer review Not commissioned; internally peer reviewed.

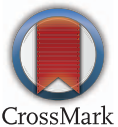

To cite Meacci F, Manfredi M, Infantino M, et al. Ann Rheum Dis 2016;75:e62.

Received 18 June 2016

Accepted 20 June 2016

Published Online First 11 July 2016

\section{SLinked}

http://dx.doi.org/10.1136/annrheumdis-2016-210091

Ann Rheum Dis 2016;75:e62. doi:10.1136/annrheumdis-2016-210078

\section{REFERENCES}

1 Park W, Yoo DH, Miranda P, et al. Efficacy and safety of switching from reference infliximab to CT-P13 compared with maintenance of CT-P13 in ankylosing spondylitis: 102-week data from the PLANETAS extension study. Ann Rheum Dis 2016; Published Online First 26 April 2016. doi:10.1136/annrheumdis-2015-208783

2 Park W, Yoo DH, Jaworski J, et al. Comparable long-term efficacy, as assessed by patient-reported outcomes, safety and pharmacokinetics, of CT-P13 and reference infliximab in patients with ankylosing spondylitis: 54-week results from the randomized, parallel-group PLANETAS study. Arthritis Res Ther 2016;18:25.

3 Yoo DH, Hrycaj P, Miranda P, et al. A randomised, double-blind, parallel-group study to demonstrate equivalence in efficacy and safety of CT-P13 compared with innovato infliximab when coadministered with methotrexate in patients with active rheumatoid arthritis: the PLANETRA study. Ann Rheum Dis 2013;72:1613-20.

4 Yoo DH, Prodanovic N, Jaworski J, et al. Efficacy and safety of CT-P13 (biosimilar infliximab) in patients with rheumatoid arthritis: comparison between switching from reference infliximab to CT-P13 and continuing CT-P13 in the PLANETRA extension study. Ann Rheum Dis 2016; Published Online First 29 April 2016. doi:10.1136/ annrheumdis-2015-208786

5 Meacci F, Manfredi M, Infantino M, et al. Anti Etanercept and anti SB4 antibodies detection: impact of the assay method. Ann Rheum Dis 2016; 75:e39.

6 Nencini F, Pratesi S, Petroni G, et al. Assays and strategies for immunogenicity assessment of biological agents. Drug Dev Res 2014;75(Suppl 1):S4-6.

7 Mikulskis A, Yeung D, Subramanyam M, et al. Solution ELISA as a platform of choice for development of robust, drug tolerant immunogenicity assays in support of drug development. J Immunol Methods 2011;365:38-49.

8 Mora JR, Obenauer-Kutner L, Vimal Patel V. Application of the Gyrolab ${ }^{\mathrm{TM}}$ platform to ligand-binding assays: a user's perspective. J Immunol Methods 2011;365: 38-49. 